\title{
Safety of maternal pertussis vaccination on pregnancy and birth outcomes: A prospective cohort study
}

\author{
Hassen Mohammed ${ }^{1}$, Claire Roberts ${ }^{1}$, Luke Grzeskowiak ${ }^{1}$, Lynne Giles ${ }^{1}$, Petra Verburg ${ }^{2}$, \\ Gus Dekker ${ }^{3}$, and Helen Marshall ${ }^{1}$ \\ ${ }^{1}$ The University of Adelaide Robinson Research Institute \\ ${ }^{2}$ University of Adelaide Robinson Institute \\ ${ }^{3}$ Lyell McEwin Hospital
}

September 11, 2020

\begin{abstract}
Abstract Objective To evaluate the safety of maternal pertussis vaccination on pregnancy and birth outcomes. Design Prospective, multicentre cohort study. Setting Two major materiality hospitals in South Australia. Population A total of 1364 low-risk nulliparous women with a singleton pregnancy recruited at 9-16 weeks' gestation between 2015 to 2018. Methods Participants were followed prospectively, with vaccination (confirmed by medical records), extensive amounts of pregnancy and birth outcome data collected by research midwives. Adjusted relative risks (aRRs) and hazard ratios (aHRs) were estimated accounting for time-varying vaccine exposure and the temporal nature of each outcome. Main Outcome Measures Pregnancy and birth outcomes. Results Of the 1272 women included in this study, 80.1\% ( $\mathrm{n}=1019)$ received maternal pertussis vaccination. Vaccinated women had an average 0.22 weeks $(95 \%$ CI $0.001,0.44)$ longer gestation at delivery compared to unvaccinated women. Maternal pertussis vaccination was not associated with chorioamnionitis (aRR 0.71, 95\% CI 0.27,1.82), gestational hypertension (aHR 1.24, 95\% CI, 0.66, 2.30), preeclampsia (aHR 0.75, 95\% CI 0.47, 1.18) nor preterm birth (aHR 0.99, 95\% CI 0.47, 2.07). Neither risk of low birth weight (aHR 0.72, 95\% CI 0.41, 1.27) nor small for gestational age infants (aHR 0.67,95\% CI 0.29 , 1.55 ) were increased following maternal pertussis vaccination. No associations between pertussis vaccination during pregnancy and adverse birth outcomes including admission to the neonatal care unit, low Apgar scores, and mechanical ventilation were observed. Conclusions Our study provides reassuring evidence of the safety of maternal pertussis vaccination with no increased risk of adverse pregnancy and birth outcomes.
\end{abstract}

Title: Safety of maternal pertussis vaccination on pregnancy and birth outcomes: A prospective cohort study

Authors: Hassen Mohammed, ${ }^{\text {a, b }}$ Claire T Roberts, ${ }^{\text {b, c }}$ Luke E Grzeskowiak, ${ }^{\text {, }}{ }^{\text {d }}$ Lynne C Giles, ${ }^{\text {b, e }}$ Petra E Verburg, ${ }^{\mathrm{b}}$ Gustaaf A Dekker, ${ }^{\mathrm{b}, \mathrm{f}}$ Helen S Marshall, ${ }^{\mathrm{a}, \mathrm{b}}$

\section{Affiliations}

a Vaccinology and Immunology Research Trials Unit, Women's and Children's Health Network, Adelaide, South Australia, Australia

${ }^{\mathrm{b}}$ Robinson Research Institute, Adelaide Medical School, University of Adelaide, Adelaide, SA, Australia

${ }^{\mathrm{c}}$ Flinders Health and Medical Research Institute, Flinders University, Bedford Park, South Australia, Australia

d SA Pharmacy, Flinders Medical Centre, SA Health, Bedford Park, Adelaide, Australia

e School of Public Health, The University of Adelaide, Adelaide, South Australia, Australia 
f Women's and Children's Division, Lyell McEwin Hospital, Elizabeth Vale, South Australia, Australia

Correspondence: Prof. Helen Marshall, Vaccinology and Immunology Research Trials Unit, Women's and Children's Hospital, 72 King William Road, North Adelaide 5006, South Australia: Phone: 81618115

Email: helen.marshall@adelaide.edu.au

A shortened running title: Safety of maternal pertussis vaccination

\section{Abstract}

\section{Objective}

To evaluate the safety of maternal pertussis vaccination on pregnancy and birth outcomes.

\section{Design}

Prospective, multicentre cohort study.

\section{Setting}

Two major materiality hospitals in South Australia.

\section{Population}

A total of 1364 low-risk nulliparous women with a singleton pregnancy recruited at 9-16 weeks' gestation between 2015 to 2018 .

\section{Methods}

Participants were followed prospectively, with vaccination (confirmed by medical records), extensive amounts of pregnancy and birth outcome data collected by research midwives. Adjusted relative risks (aRRs) and hazard ratios (aHRs) were estimated accounting for time-varying vaccine exposure and the temporal nature of each outcome.

\section{Main Outcome Measures}

Pregnancy and birth outcomes.

\section{Results}

Of the 1272 women included in this study, $80.1 \%(\mathrm{n}=1019)$ received maternal pertussis vaccination. Vaccinated women had an average 0.22 weeks $(95 \%$ CI $0.001,0.44)$ longer gestation at delivery compared to unvaccinated women. Maternal pertussis vaccination was not associated with chorioamnionitis (aRR 0.71, 95\% CI 0.27,1.82), gestational hypertension (aHR 1.24, 95\% CI, 0.66, 2.30), preeclampsia (aHR 0.75, 95\% CI $0.47,1.18$ ) nor preterm birth (aHR 0.99, 95\% CI 0.47, 2.07). Neither risk of low birth weight (aHR 0.72, $95 \%$ CI $0.41,1.27$ ) nor small for gestational age infants (aHR 0.67,95\% CI $0.29,1.55$ ) were increased following maternal pertussis vaccination. No associations between pertussis vaccination during pregnancy and adverse birth outcomes including admission to the neonatal care unit, low Apgar scores, and mechanical ventilation were observed.

\section{Conclusions}

Our study provides reassuring evidence of the safety of maternal pertussis vaccination with no increased risk of adverse pregnancy and birth outcomes.

\section{Keywords}

Maternal vaccination, Pertussis, Tdap, Safety, Pregnant women, Infants

\section{Tweetable abstract}


Reassuring evidence of no increased risk of adverse pregnancy and birth outcomes following pertussis vaccination during pregnancy.

\section{Funding}

No funding.

\section{Introduction}

There has been a global resurgence in pertussis in recent years, with the highest rates of hospitalization and death in infants too young to be fully protected by routine childhood vaccination series. ${ }^{1-3}$ Infection of young infants occurs primarily through household contacts, with new mothers identified as the most common sources of transmission. ${ }^{4}$ Pertussis vaccination during pregnancy protects the mother from pertussis infection but more importantly offers passive immunity to her newborn via transplacental transport of maternal antibodies and is currently considered the most successful and effective intervention to prevent early infant disease. ${ }^{5}$ Maternal pertussis vaccination at least seven days before delivery has been shown to protect against pertussis in up to $91 \%$ of infants in the first two months of life. ${ }^{6,7}$ Following the implementation of government funded maternal pertussis vaccination programs for pregnant women in different countries there has been an increasing general pertussis vaccine uptake in pregnancy. ${ }^{8}$ However uptake varies across and within countries in pregnant women and is suboptimal. ${ }^{8}$ One of the reasons for low pertussis vaccination uptake is healthcare providers' and/or women's concerns about the safety of the vaccine during pregnancy. ${ }^{9,} 10$

Several systematic reviews ${ }^{11-14}$ have demonstrated that maternal pertussis vaccination during pregnancy does not adversely affect obstetric or neonatal outcomes, although the quality of the evidence in underlying studies is low. Many previous studies have investigated the safety of pertussis vaccination during pregnancy retrospectively, due to the relatively cheaper cost, fewer ethical concerns, and difficulty in recruiting pregnant women to randomized controlled trials. Three retrospective cohort studies ${ }^{15-17}$ reported a small but statistically significant increased relative risk of chorioamnionitis in women who had received pertussis vaccination during pregnancy. This unreplicated finding merits further investigation since chorioamnionitis is associated with severe short-term and long-term neonatal complications. ${ }^{18}$ Most observational studies have been unable to account for the time-dependent nature of exposure to pertussis vaccination during pregnancy. To accurately determine any risk of maternal pertussis vaccination for pregnant women and their infants, prospectively designed studies incorporating statistical approaches suitable for analysing time-dependent associations between maternal pertussis vaccine exposure on pregnancy and birth outcomes are warranted. The primary aim was to prospectively assess pregnancy and birth outcomes following pertussis vaccination during pregnancy considering time-dependent vaccine exposure and using the most comprehensive set of potential confounding variables considered to date.

\section{Methods}

The current study draws on data collected as part of a prospective cohort study (STOP), which aims to develop screening tests to identify adverse pregnancy outcomes. Healthy nulliparous pregnant women were recruited at two major maternity hospitals, the Lyell McEwin Hospital, the tertiary hospital serving a lower socio-economic community in Adelaide's Northern suburbs and the Women's and Children's Hospital, the primary tertiary maternity hospital for complex care in metropolitan Adelaide, South Australia. Between March 2015 and December 2017, nulliparous women with a singleton pregnancy attending their first antenatal clinic between $9^{+0}$ and $16^{+0}$ weeks' gestation were enrolled as part of the prospective cohort study described elsewhere. ${ }^{19,}{ }^{20}$ Women were excluded if they were considered already at high risk of pregnancy complications at screening (i.e. experienced three or more previous miscarriages or with pre-existing hypertension or diabetes). Participants were followed prospectively, with vaccination, pregnancy, and birth outcome data collected by research midwives. As pertussis vaccination was recommended to be administered between 
28-32 weeks' gestation, we restricted the analyses to data from women whose pregnancies reached at least 32 weeks' gestation to allow all women to have had the opportunity to receive the pertussis vaccine.

The exposure of interest was pertussis-containing vaccine (tetanus-diphtheria-acellular pertussis: dTpa). A research midwife interviewed and collected maternal vaccination status of the women during their study visit interview at 32-36 weeks' gestation. Maternal vaccination date and gestation at administration were recorded. Following delivery, a research midwife verified final vaccination status by reviewing PregnancyHand-Held-Records and interviewing women. Pregnancy-Hand-Held-Records are the primary medical record of pregnancy care in South Australia.

Pregnancy outcomes assessed were gestational hypertension $(\mathrm{GH})$, preeclampsia (PE), chorioamnionitis and/or funisitis, pre-delivery hospitalisation due to acute respiratory infections or influenza-like illness, premature rupture of membranes (PPROM), placental abruption, spontaneous preterm birth and preterm birth. Birth outcomes included small for gestational age (SGA), low birthweight $(<2500 \mathrm{~g})$ (LBW), LBW at term ([?] 37 weeks' gestation), Apgar scores at 1 and $5 \mathrm{~min}$, neonatal care unit admissions, respiratory distress and mechanical ventilation.

Pregnancy and birth complications were diagnosed using the Brighton Collaboration consensus list of terms, ${ }^{21}$ and The Global Alignment of Immunization Safety Assessment in Pregnancy (GAIA) project. ${ }^{22}$ GH was defined as hypertension [systolic BP (SBP) [?] $140 \mathrm{mmHg}$ or diastolic BP (DBP) [?] $90 \mathrm{mmHg}$ ] after 20 weeks of gestation in previously normotensive women. PE was defined as GH with proteinuria (24 h urinary protein [?] $300 \mathrm{mg}$ or spot urine protein: creatinine ratio [?] $30 \mathrm{mg} / \mathrm{mmol}$ creatinine or urine dipstick protein [?] 2+) or any multi-organ complication of PE, including SGA age infant. Suspected Chorioamnionitis was considered to be present only with a physician's diagnosis, which was dependent on maternal fever [?] 38 ${ }^{\circ} \mathrm{C}$, with at least two of the following: maternal tachycardia, fetal tachycardia, uterine tenderness, foul odour of amniotic fluid, or maternal leucocytosis or increased CRP. Funisitis is a histopathologic diagnosis, and it is the extension of infection or inflammation to the umbilical cord. Preterm birth (PTB) was defined as any birth after $20^{+0}$ and before $37^{+0}$ weeks of gestation. SGA was defined as neonates with a birthweight $<10^{\text {th }}$ percentile customized for maternal factors including maternal height, booking weight, ethnicity and gestational age at delivery.

During the first study visit at 9-16 weeks' gestation, information was obtained regarding baseline sociodemographic, lifestyle and clinical characteristics including age, ethnicity, level of education, household income, employment, exercise, smoking, supplement use, intake of alcohol and recreational drugs, medical and obstetric history, and complications during the current pregnancy. Participants also completed questionnaires assessing stress levels in the past month (Perceived Stress Scale (PSS-10)) ${ }^{23}$, current anxiety symptoms (short form of the Spielberger State-Trait Anxiety Inventory (STAI)) ${ }^{24}$ and depressive symptoms during pregnancy (Edinburgh Postnatal Depression Scale (EPDS)). ${ }^{25}$

Demographic, lifestyle and clinical characteristics of participants were summarized descriptively by pertussis vaccination exposure during pregnancy. Continuous variables were summarized as mean with standard deviation (SD) or median with interquartile range (IQR), as appropriate, while counts and percentages were used to summarize categorical variables. To assess if there was an association between maternal pertussis vaccination status and each of the outcome variables, we initially conducted independent samples t-tests and Mann-Whitney U tests, as appropriate, for continuous variables and chi-square tests of association for binary and categorical variables.

The timing for vaccination exposures and time-at-risk windows were calculated for each time-sensitive pregnancy and birth outcome, accounting for the temporal nature of each outcome of interest. For instance, women were at risk for PTB from $20^{+0}$ until $36^{+6}$ weeks of gestation but had to attain at least 32 weeks' gestation for inclusion in the analysis data set. Cox proportional-hazards models with gestational age in weeks as the underlying time metric were used to derive hazard ratios (HRs) that compared the hazard rates between vaccinated and unvaccinated women for time-sensitive outcomes. Vaccination status was treated as a time-varying exposure in these models, in that each vaccinated woman's pregnancy was divided into 
unvaccinated and vaccinated exposure periods. Thus, a woman who did not receive the vaccine during pregnancy was classified into the unvaccinated group in any risk set, whereas a woman who received the vaccine at some point during her pregnancy was initially classified as unvaccinated and then classified as vaccinated from the time at vaccination onwards.

We used log-binomial models to estimate risk ratios (RR) and adjusted risk ratios (aRR) comparing the risk of late onset or early postpartum adverse pregnancy outcomes and time-independent birth outcomes between vaccinated and unvaccinated mothers. A multivariable linear regression model was applied to compare the difference in mean gestational age at delivery and mean birthweight by maternal pertussis vaccination status. For all multivariable models, age, level of education, ethnicity, gravidity, annual household income, alcohol intake, recreational drug use, smoking, pre-pregnancy body mass index (BMI), use of micronutrient supplements, asthma, assisted reproductive treatment and current psychological states were amongst the variables selected as potential confounders based on evidence in the literature ${ }^{11-14}$ guided by directed acyclic graphs. Sensitivity analyses were conducted in all multivariable models to evaluate whether the effects of maternal pertussis vaccination on pregnancy and birth outcomes were maintained after adjustment for receipt of maternal influenza vaccination. The overall missing covariate data at baseline was $<5 \%$ and therefore all available data were used in the analyses of all pre-specified outcomes. For all analyses, p values $<$ 0.05 were considered statistically significant. We did not correct for multiple comparisons to minimize the risk of Type II errors. Data were recorded in a REDCap ${ }^{26,27}$ online database and all statistical analyses were conducted using Stata version 15. Written informed consent was obtained from all women. Personal identifying information in the study database was eliminated to ensure that confidentiality of all patients' records was maintained. The STOP study protocol was approved by the Human Research Committee of the Women's and Children's Hospital Adelaide Australia (HREC/14/WCHN/90). ${ }^{19}$

\section{Results}

Of 1364 pregnant women enrolled, 12 withdrew access to their medical records, six were lost to follow up, and 14 delivered elsewhere; all 32 women were excluded from our final analyses. After excluding 60 pregnancies that ended before 32 weeks' gestation, our final cohort consisted of 1272 women (Figure 1). At enrolment, the mean (SD) maternal age of nulliparous women was 25.9 (4.9) years (range: 15-45 years). A total of 1040 $(81.7 \%)$ women attended their first antenatal visit in first trimester at a mean gestational age of $11.4(1.7)$ weeks.

The uptake of pertussis vaccination was $80.1 \%$. Of the 1019 women who received maternal pertussis vaccination, $77.8 \%(\mathrm{n}=790)$ received the pertussis vaccine within the recommended timeframe of $28-32$ weeks, $2.7 \%$ $(\mathrm{n}=28)$ before 28 weeks (range 12-27 weeks) and $19.4 \%$ after 32 weeks' gestation. The mean gestational age at vaccination was 30.3 (2.8) weeks. Both pertussis and influenza vaccinations were administered in 555 of $1272(43.6 \%)$ pregnancies. Those women who did not receive maternal pertussis vaccination were more likely to have no previous history of termination and/or miscarriage, be younger, in the healthy weight range, smoke cigarettes, use illicit drugs, physically inactive, in the lowest household income group, have lower educational attainment and were less likely to take micronutrient supplements pre-conception or during pregnancy compared with vaccinated pregnant women. Women who received pertussis vaccination were more likely to receive influenza vaccine (Table 1).

Of the 1272 women, 82 had a PTB (6.4\%). The mean gestational age at delivery was 39.4 (1.5) weeks. After adjusting for covariates, women who had received pertussis vaccination during pregnancy had on average 0.22 weeks $(95 \%$ CI $0.001,0.44)$ longer gestation at delivery than unvaccinated women (Table 2 ). The time-dependent Cox proportional hazards regression model shows that receiving pertussis vaccination during pregnancy did not increase the risk of PTB (aHR 0.99, 95\% CI 0.47, 2.07), spontaneous PTB (aHR 0.99, 95\% CI $0.57,1.70$ ) or PPROM (aHR 1.01, 95\% CI 0.52, 1.97) (Table 2). Our time dependent analyses also indicated that there was no increased risk for maternal hypertensive disorders (i.e. GH, PE), or hospitalisation with acute respiratory/influenza-like illness among vaccinated women compared with unvaccinated women 
(Table 2). In log-binomial models, maternal pertussis vaccination was not associated with chorioamnionitis, placental abruption, or postpartum hemorrhage (Table 3).

Of all 1272 births included in this study, 1269 (99.7\%) were live births and three $(0.2 \%)$ were stillbirths at term. The majority of infants $(93.5 \%, \mathrm{n}=1190)$ were born at term. The mean birthweight of the infants was 3368 grams. In the multivariable linear regression model, infants born to vaccinated mothers were on average $44.6 \mathrm{~g}$ heavier than infants born to unvaccinated mothers but the confidence intervals were wide (95\% CI $-26.0 \mathrm{~g}, 115.3 \mathrm{~g}$ ) (Table 2). All birth outcomes had an adjusted relative risk of less than one, although all confidence intervals were wide (Table $2 \& 3$ ).

The time-dependent Cox proportional hazards regression models demonstrate that receiving pertussis vaccination during pregnancy was not associated with increased risk of delivering LBW infants (aHR 0.72, 95\% CI $0.41,1.27$ ), LBW at term infants (aHR 0.67, 95\% CI 0.29, 1.55) or SGA infants (aHR 0.80, 95\% CI 0.53, 1.20) (Table 2). Our log-binomial models also suggest there was no increased risk of other adverse perinatal outcomes including Apgar scores $<7$ at one and five minutes, admission to the neonatal care unit, mechanical ventilation, and respiratory distress syndrome following pertussis vaccination during pregnancy (Table 3 ). Adjustment for influenza vaccination did not appreciably change any of the findings (Table S1 \& S2).

\section{Discussion}

\section{Main findings}

This study provided a unique prospective assessment of accurate pregnancy and infant data with confirmed maternal vaccination status. The analytical framework treated pertussis vaccination as a time-varying exposure and computed time at risk windows for each of the time sensitive outcomes of interest and adjusted for a comprehensive set of confounding factors to reaffirm that maternal pertussis vaccination is safe for both the mothers and their newborn infants.

\section{Strengths and Limitations}

The major strength of this study is the prospective cohort design that recruited a large number of nulliparous women with singleton pregnancies at low risk for obstetric complications at two major maternity hospitals. Vaccinated women in our study were more likely to engage in healthy lifestyles i.e. pregnancy micronutrient supplementation, regular exercise, non-smoking than unvaccinated women. The analysis framework used herein adjusted for putative risk factors, including psychosocial factors, to mitigate the impact of any 'healthy vaccinee bias' on our findings. However, we cannot rule out the possibility of residual confounding. Our use of Cox proportional-hazards models accounting for time-varying vaccine exposure during pregnancy minimized the introduction of immortal time bias in our data. ${ }^{25}$ The potential for this bias arises because the opportunity for vaccination increases the longer a woman remains pregnant. ${ }^{28}$ Furthermore, many studies use the earliest recommended maternal pertussis vaccination time (i.e. 28 weeks' gestation in this case) as a cut-off point to restrict their data but pregnancies must survive within the recommended timeframe (i.e. 28-32 weeks' gestation) to be eligible to receive the vaccines. Hence, immortal time bias may also be present in studies of maternal pertussis vaccination evaluating adverse pregnancy outcomes that develop in mid-tolate pregnancy, including $\mathrm{PE}$ and $\mathrm{GH}$, where the bias may attenuate the true relative risk. Our analytic approach used 32 instead of 28 weeks' gestation as the cut-off point in order to allow all women to have had the chance to receive the recommended pertussis vaccination in that optimal 4 -week window. This may have reduced the introduction of immortal time bias in our analyses. Additionally, including follow-up time during which pregnancies are no longer at risk of some adverse outcomes (e.g. gestation after 37 weeks considered for PTB outcomes) can lead to incorrect estimation of the effect of maternal vaccination on the outcome of interest but our time-to-event analytic approach minimized the risk of these biases occurring. Another major strength of our study is confirmed maternal vaccination status. As this study was a secondary analysis, we 
did not conduct an a priori power analysis to show sample size adequacy. A post-hoc power analysis was not conducted as there is a rich literature, in both medical and statistical journals, warning against post-hoc power calculations. ${ }^{29,} 30$ However, the cohort was originally powered on the basis of $25 \%$ of women affected by pregnancy complications (preeclampsia, small for gestational age birth, spontaneous preterm birth and gestational diabetes mellitus). ${ }^{19}$

\section{Interpretation}

Our Cox proportional hazards models accounting for the time-dependent nature of exposure to vaccination during pregnancy, thereby avoiding the introduction of immortal time bias to our analyses, found no association between maternal pertussis vaccination and PTB, spontaneous PTB, nor PPROM, reaffirming the conclusion from previous systematic reviews. ${ }^{11-14}$

In keeping with previous studies ${ }^{11,12}$, our findings demonstrated no association between maternal pertussis vaccination and gestational hypertensive disorders. The new Australian guidelines recommend pregnant women to receive a pertussis vaccine from 20 weeks of gestation rather than 28 weeks' to maximize the opportunity for vaccination to protect all infants, including preterm infants. ${ }^{31}$ Administration of maternal pertussis vaccination from 20 weeks' can align with other key routine antenatal visits such as morphology scanning and gestational diabetes testing, potentially improving the uptake of pertussis vaccination among pregnant women. However, there is a need for continued surveillance and monitoring to confirm that a broader window for pertussis vaccination during pregnancy is safe for the pregnant mother and the newborn.

Our study demonstrates that maternal pertussis vaccination was not associated with chorioamnionitis. In contrast, three large retrospective studies ${ }^{15-17}$ conducted in the USA showed receipt of pertussis vaccination during pregnancy was associated with a small but significant increase in risk of developing chorioamnionitis. These studies ${ }^{15-17}$ used commercial health data and ICD codes for identifying chorioamnionitis from electronic medical records with no clinical case definition. Coding for commercial reasons, such as insurance claims, is potentially subject to favoring more severe diagnoses and might be prone to poor external validity, selection bias, confounding and misclassification bias. ${ }^{32}$ Furthermore, these studies did not find an association with an increased risk of PTB, which is an expected major clinical sequel of chorioamnionitis and most women with chorioamnionitis had at least one pre-existing risk factor for this complication. This suggests the observed relation between receipt of pertussis vaccination during pregnancy and chorioamnionitis was unlikely to be casual, and is probably more reflective of residual confounding affecting the results in these studies.

In our study, we found an association between maternal pertussis vaccination during pregnancy and longer gestation. There are no known biologically plausible direct effects of pertussis vaccination on pregnancy duration but women who remained pregnant longer have more opportunity to have received pertussis vaccine in the late third trimester of pregnancy. This may have created a spurious relationship between pregnancy duration and time-varying pertussis vaccine exposure during pregnancy because linear regression analysis is not suited to include both the event and time aspects in the model.

Our study provides further assurance that pertussis vaccination during pregnancy is not associated with any adverse birth outcomes including LBW or SGA births, consistent with previous findings. ${ }^{11-14}$ Receipt of pertussis vaccination during pregnancy was not associated with increased risk of perinatal outcomes including admission to the neonatal care unit, respiratory distress, Apgar scores $<7$ nor need for mechanical ventilation at birth compared with infants born to unvaccinated women. ${ }^{11-14}$

\section{Conclusions}

The present study offers a unique prospective and robust assessment of the safety of pertussis vaccination during pregnancy and provides reaffirming evidence of the safety of maternal pertussis vaccination for both 
mothers and their infants. Evidence presented in our study provide further reassurance to expecting women and healthcare providers about the safety of pertussis vaccination during pregnancy and supports recommendations for pertussis vaccination during pregnancy to prevent morbidity and mortality associated with early-infant pertussis disease. The study findings also aid evidence-based decision making for clinicians and policy makers in countries considering implementation of universal maternal pertussis immunisation programs.

\section{Disclosures}

HSM has been an investigator on clinical trials funded by pharmaceutical companies including Pfizer, GSK Sanofi-Pasteur, Novartis. Her institution receives funding for Investigator led research. HSM receives no personal payments from Industry. The remaining authors have no conflicts of interest to declare.

\section{Contribution to authorship}

HM, CTR, LEG, LCG and HSM have all contributed to the planning and design of the study, to the interpretations of the data. HM performed data analyses and prepared the first and final drafts of the manuscript. GD and PV have critically revised the manuscript. All named authors were involved in critically reviewing the content, and have approved the final version for publication.

\section{Details of ethical approval}

No ethical approval was required for this study as all data were drawn from STOP cohort. The STOP study protocol was registered at www.anzctr.org.au (registration number ACTRN12614000985684) and was approved by the Human Research Committee of the Women's and Children's Hospital Adelaide Australia (HREC/14/WCHN/90) on $16^{\text {th }}$ September 2014.

\section{Funding}

No funding source directly supported the work in this manuscript.

\section{Acknowledgments}

The STOP Study was funded by a University of Adelaide Grant awarded to CTR. CTR was supported by a Lloyd Cox Professorial Research Fellowship from the University of Adelaide and is currently supported by an Australian National Health and Medical Research Council (NHMRC) Investigator Grant (GNT1174971) and a Matthew Flinders Fellowship from Flinders University. LEG is supported by a Mid-Career Fellowship from The Hospital Research Foundation.

\section{Supporting information}

The following supplementary materials are available for this article:

Table S1 . Crude and adjusted hazard ratios sensitivity analysis for time-based pregnancy and birth outcomes by maternal pertussis vaccination status adjusted for maternal influenza vaccination at two obstetric hospitals in South Australia 2015-2018.

Table S2. Pregnancy and birth outcomes following pertussis vaccination during pregnancy adjusted for maternal influenza vaccination at two obstetric hospitals in South Australia 2015-2018.

\section{References}

1. Munoz FM. Pertussis in infants, children, and adolescents: diagnosis, treatment, and prevention. Semin Pediatr Infect Dis. 2006;17(1):14-9. 
2. Cortese MM, Baughman AL, Zhang R, Srivastava PU, Wallace GS. Pertussis hospitalizations among infants in the United States, 1993 to 2004. Pediatrics. 2008;121(3):484-92.

3. Quinn HE, McIntyre PB. Pertussis epidemiology in Australia over the decade 1995-2005-trends by region and age group. Communicable diseases intelligence quarterly report. 2007;31(2):205-15.

4. Wiley KE, Zuo Y, Macartney KK, McIntyre PB. Sources of pertussis infection in young infants: a review of key evidence informing targeting of the cocoon strategy. Vaccine. 2013;31(4):618-25.

5. Amirthalingam G. Strategies to control pertussis in infants. Arch Dis Child. 2013;98(7):552-5.

6. Amirthalingam G, Andrews N, Campbell H, Ribeiro S, Kara E, Donegan K, et al. Effectiveness of maternal pertussis vaccination in England: an observational study. Lancet. 2014;384(9953):1521-8.

7. Baxter R, Bartlett J, Fireman B, Lewis E, Klein NP. Effectiveness of Vaccination During Pregnancy to Prevent Infant Pertussis. Pediatrics. 2017;139(5).

8. Mohammed H, McMillan M, Roberts CT, Marshall HS. A systematic review of interventions to improve uptake of pertussis vaccination in pregnancy. PLoS One. 2019;14(3):e0214538.

9. Wilson RJ, Paterson P, Jarrett C, Larson HJ. Understanding factors influencing vaccination acceptance during pregnancy globally: A literature review. Vaccine. 2015;33(47):6420-9.

10. MacDougall DM, Halperin SA. Improving rates of maternal immunization: Challenges and opportunities. Hum Vaccin Immunother. 2016;12(4):857-65.

11. Furuta M, Sin J, Ng ESW, Wang K. Efficacy and safety of pertussis vaccination for pregnant women a systematic review of randomised controlled trials and observational studies. BMC Pregnancy Childbirth. 2017;17(1):390-.

12. McMillan M, Clarke M, Parrella A, Fell DB, Amirthalingam G, Marshall HS. Safety of Tetanus, Diphtheria, and Pertussis Vaccination During Pregnancy: A Systematic Review. Obstet Gynecol. 2017;129(3):56073.

13. Vygen-Bonnet S, Hellenbrand W, Garbe E, von Kries R, Bogdan C, Heininger U, et al. Safety and effectiveness of acellular pertussis vaccination during pregnancy: a systematic review. BMC Infect Dis. 2020;20(1):136.

14. D'Heilly C, Switzer C, Macina D. Safety of Maternal Immunization Against Pertussis: A Systematic Review. Infectious Diseases and Therapy. 2019;8(4):543-68.

15. Kharbanda EO, Vazquez-Benitez G, Lipkind HS, et al. Evaluation of the association of maternal pertussis vaccination with obstetric events and birth outcomes. JAMA. 2014;312(18):1897-904.

16. Layton JB, Butler AM, Li D, Boggess KA, Weber DJ, McGrath LJ, et al. Prenatal Tdap immunization and risk of maternal and newborn adverse events. Vaccine. 2017;35(33):4072-8.

17. DeSilva M, Vazquez-Benitez G, Nordin JD, Lipkind HS, Klein NP, Cheetham TC, et al. Maternal Tdap vaccination and risk of infant morbidity. Vaccine. 2017;35(29):3655-60.

18. Johnson CT, Farzin A, Burd I. Current management and long-term outcomes following chorioamnionitis. Obstet Gynecol Clin North Am. 2014;41(4):649-69.

19. Australian New Zealand Clinical Trials Registry: Screening Tests to identify poor Outcomes in Pregnancy (STOP) Study 2014. Registration number ACTRN12614000985684. [cited 01/09/2020]. Available from: https://www.anzctr.org.au/Trial/Registration/TrialReview.aspx?id=366996.

20. Mohammed H, Roberts CT, Grzeskowiak LE, Giles L, Leemaqz S, Dalton J, et al. Psychosocial determinants of pertussis and influenza vaccine uptake in pregnant women: A prospective study. Vaccine. 2020;38(17):3358-68. 
21. Munoz FM, Eckert LO, Katz MA, Lambach P, Ortiz JR, Bauwens J, et al. Key terms for the assessment of the safety of vaccines in pregnancy: Results of a global consultative process to initiate harmonization of adverse event definitions. Vaccine. 2015;33(47):6441-52.

22. Jones CE, Munoz FM, Kochhar S, Vergnano S, Cutland CL, Steinhoff M, et al. Guidance for the collection of case report form variables to assess safety in clinical trials of vaccines in pregnancy. Vaccine. 2016;34(49):6007-14.

23. Cohen S, Kamarck T, Mermelstein R. A global measure of perceived stress. J Health Soc Behav. 1983;24(4):385-96.

24. Marteau TM, Bekker H. The development of a six-item short-form of the state scale of the Spielberger State-Trait Anxiety Inventory (STAI). Br J Clin Psychol. 1992;31 ( Pt 3):301-6.

25. Cox JL, Holden JM, Sagovsky R. Detection of postnatal depression. Development of the 10-item Edinburgh Postnatal Depression Scale. Br J Psychiatry. 1987;150:782-6.

26. Harris PA, Taylor R, Minor BL, Elliott V, Fernandez M, O'Neal L, et al. The REDCap consortium: Building an international community of software platform partners. J Biomed Inform. 2019;95:103208.

27. Harris PA, Taylor R, Thielke R, Payne J, Gonzalez N, Conde JG. Research electronic data capture (REDCap)-a metadata-driven methodology and workflow process for providing translational research informatics support. J Biomed Inform. 2009;42(2):377-81.

28. Hutcheon JA, Savitz DA. Invited Commentary: Influenza, Influenza Immunization, and Pregnancy-It's About Time. Am J Epidemiol. 2016;184(3):187-91.

29. Senn SJ. Power is indeed irrelevant in interpreting completed studies. BMJ (Clinical research ed). 2002;325(7375):1304-.

30. Hoenig JM, Heisey DM. The Abuse of Power. The American Statistician. 2001;55(1):19-24.

31. The Australian Government Department of Health and Ageing. Australian Technical Advisory Group on Immunisation Canberra2019.

32. Hyman J. The limitations of using insurance data for research. J Am Dent Assoc. 2015;146(5):283-5.

Table 1: Maternal characteristics of vaccinated and unvaccinated pregnant women who delivered at two obstetric hospitals in South Australia, 2015 to 2018 ( $N=1272)$

\begin{tabular}{|c|c|c|}
\hline Variable & $\begin{array}{l}\text { Vaccinated women } N=1019 \text {, } \\
\text { n (\%) }\end{array}$ & $\begin{array}{l}\text { Unvaccinated women } \mathrm{N}=\mathbf{2 5 3} \text {, } \\
\text { n }(\%)\end{array}$ \\
\hline Maternal age (years) 15-19 & $85(8.3) 289(28.3) 390(38.2)$ & $44(17.3) 97$ (38.3) 68 (26.8) 44 \\
\hline $20-2425-29>30$ & $255(25.0)$ & $(17.3)$ \\
\hline Maternal age, mean (SD) & $26.2 \pm 4.9$ & $24.5 \pm 4.9$ \\
\hline $\begin{array}{l}\text { Race/ethnicity Caucasian } \\
\text { Aboriginal/TSI Others }\end{array}$ & $850(83.4) 15(1.4) 154(15.1)$ & $204(80.6) 8(3.1) 41(16.2)$ \\
\hline $\begin{array}{l}\text { Household annual income } \\
\text { in AUD }<40,00040,001-70,000 \\
70,001-105,000>105,001 \\
\text { Missing }\end{array}$ & $\begin{array}{l}212(20.8) 221(21.6) 283(27.7) \\
293(28.7) 10(0.9)\end{array}$ & $\begin{array}{l}81(32.0) 62(24.5) 44(17.3) 61 \\
(24.1) 5(1.9)\end{array}$ \\
\hline $\begin{array}{l}\text { Maternal education [?] } \\
\text { Secondary school qualification } \\
\text { Diploma/certificate Bachelor's } \\
\text { or higher degree Missing }\end{array}$ & $\begin{array}{l}436(42.7) 365(35.8) 216(21.2) \\
2(0.2)\end{array}$ & $\begin{array}{l}119(47.0) 90(35.5) 42(16.6) 2 \\
(0.7)\end{array}$ \\
\hline $\begin{array}{l}\text { Total years of formal education, } \\
\text { mean (SD) }\end{array}$ & $13.4 \pm 2.4$ & $13.0 \pm 2.6$ \\
\hline
\end{tabular}




\begin{tabular}{|c|c|c|}
\hline Variable & $\begin{array}{l}\text { Vaccinated women } \mathrm{N}=1019, \\
\mathrm{n}(\%)\end{array}$ & $\begin{array}{l}\text { Unvaccinated women } \mathrm{N}=253 \text {, } \\
\text { n }(\%)\end{array}$ \\
\hline $\begin{array}{l}\text { Moderate exercise during } \\
\text { 1st } \\
\text { trimester/pre-pregnancy [?] } \\
4 \text { per week } 1-3 \text { per week Never } \\
\text { Missing }\end{array}$ & $\begin{array}{l}126(12.3) 493(48.3) 393(38.5) \\
7(0.6)\end{array}$ & $\begin{array}{l}22(8.7) 118(46.6) 110(43.4) 3 \\
(1.1)\end{array}$ \\
\hline Gravidity >1 & $296(29.0)$ & $57(22.5)$ \\
\hline Asthma & $146(14.3)$ & $31(12.5)$ \\
\hline $\begin{array}{l}\text { Assisted reproductive } \\
\text { technology (IVF) }\end{array}$ & $60(5.8)$ & $10(3.9)$ \\
\hline $\begin{array}{l}\text { Pre-pregnancy BMI } \\
(\mathrm{kg} / \mathbf{m} 2)<18.5 \text { (Under) } \\
18.5-24 \text { (Normal) } 25-29.9 \\
\text { (Overweight) [?] } 30 \text { (Obese) }\end{array}$ & $\begin{array}{l}16(1.5) 389(38.1) 274(26.8) \\
340(33.3)\end{array}$ & $\begin{array}{l}9(3.5) 110(43.4) 81(32.0) 53 \\
(20.9)\end{array}$ \\
\hline $\begin{array}{l}\text { Pre-pregnancy BMI }(\mathrm{kg} / \mathrm{m} 2) \text {, } \\
\text { mean (SD) }\end{array}$ & $28.2 \pm 7.1$ & $26.7 \pm 6.7$ \\
\hline $\begin{array}{l}\text { Smoking status at } \mathbf{9 - 1 6} \\
\text { weeks' gestation Current } \\
\text { smoker Quit during pregnancy } \\
\text { Non-smoker Missing }\end{array}$ & $\begin{array}{l}87(8.5) 112(10.9) 815(79.9) 5 \\
(0.4)\end{array}$ & $\begin{array}{l}34(13.4) 25(9.8) 192(75.8) 2 \\
(0.7)\end{array}$ \\
\hline $\begin{array}{l}\text { Illicit drug use during 1st } \\
\text { trimester/pre-pregnancy }\end{array}$ & $51(5.0)$ & $26(10.2)$ \\
\hline $\begin{array}{l}\text { Multivitamin and mineral } \\
\text { supplements use } \\
\text { Pre-conception and 1st } \\
\text { trimester 1st trimester None } \\
\text { Missing }\end{array}$ & $\begin{array}{l}248(24.3) 548(53.7) 217(21.3) \\
6(0.5)\end{array}$ & $\begin{array}{l}37(14.6) 133(52.5) 82(32.4) 1 \\
(0.4)\end{array}$ \\
\hline $\begin{array}{l}\text { Psychological measures at } \\
\text { 9-16 weeks' gestation } \\
\text { Edinburgh Perinatal Depression } \\
\text { Scale (EPDS) scores, mean } \\
\text { (SD) State and trait anxiety } \\
\text { (STAI) scores, mean (SD) } \\
\text { Perceived stress scale (PSS) } \\
\text { scores, mean (SD Missing }\end{array}$ & $\begin{array}{l}5.3 \pm 4.833 .2 \pm 11.212 .9 \pm 6.5 \\
30(2.9)\end{array}$ & $\begin{array}{l}5.7 \pm 4.533 .8 \pm 11.013 .5 \pm 6.4 \\
12(4.7)\end{array}$ \\
\hline $\begin{array}{l}\text { Gestational week of vaccine } \\
\text { administration, mean (SD) }\end{array}$ & $30.3 \pm 2.8$ & NA \\
\hline $\begin{array}{l}\text { Gestational week of vaccine } \\
\text { administration, median (IQR) }\end{array}$ & $30(26-34)$ & NA \\
\hline $\begin{array}{l}\text { Received influenza vaccination } \\
\text { during pregnancy }\end{array}$ & $555(54.4)$ & $42(16.6)$ \\
\hline
\end{tabular}

Data are mean $(\mathrm{SD})$ or $\mathrm{n}(\%)$

$\mathrm{SD}=$ standard deviations $\mathrm{IQR}=$ interquartile range $\mathrm{AUD}=$ Australian dollars. BMI=body-mass-index.

Table 2: Crude and adjusted hazard ratios for time-based pregnancy and birth outcomes by maternal pertussis vaccination status at two obstetric hospitals in South Australia 2015-2018 


\begin{tabular}{|c|c|c|c|c|c|c|c|}
\hline $\begin{array}{l}\text { Pregnancy } \\
\text { outcomes }\end{array}$ & Total a & $\begin{array}{l}\text { Unvaccinated } \\
\mathrm{N}(\%)\end{array}$ & $\begin{array}{l}\text { Vaccinated } \\
\mathrm{N}(\%)\end{array}$ & $\begin{array}{l}\text { Crude HR } \\
(95 \% \text { CI })\end{array}$ & p-value & $\begin{array}{l}\text { Adjusted }{ }^{\mathrm{c}} \\
\operatorname{aHR}(95 \% \\
\mathrm{CI})\end{array}$ & p-value \\
\hline $\begin{array}{l}\text { Gestational } \\
\text { hyperten- } \\
\text { sion } \\
\text { d }\end{array}$ & $\begin{array}{l}86 / 1267 \\
(6.7)\end{array}$ & $\begin{array}{l}10 / 249 \\
(4.0)\end{array}$ & $\begin{array}{l}76 / 1018 \\
(7.4)\end{array}$ & $\begin{array}{l}1.45(0.79 \\
2.66)\end{array}$ & 0.228 & $\begin{array}{l}1.24(0.66 \\
2.30)\end{array}$ & 0.497 \\
\hline $\begin{array}{l}\text { Preeclampsia } \\
\mathrm{d}\end{array}$ & $\begin{array}{l}116 / 1268 \\
(9.1)\end{array}$ & $\begin{array}{l}26 / 250 \\
(10.4)\end{array}$ & $\begin{array}{l}90 / 1018 \\
(8.8)\end{array}$ & $\begin{array}{l}0.77(0.49 \\
1.19)\end{array}$ & 0.246 & $\begin{array}{l}0.75(0.47 \\
1.18)\end{array}$ & 0.220 \\
\hline $\begin{array}{l}\text { Pre- } \\
\text { delivery } \\
\text { hospital- } \\
\text { ization } \\
\text { due to } \\
\text { influenza } \\
\text { like illness } \\
\text { e }\end{array}$ & $\begin{array}{l}94 / 1272 \\
(7.3)\end{array}$ & $\begin{array}{l}24 / 253 \\
(9.4)\end{array}$ & $\begin{array}{l}70 / 1019 \\
(6.8)\end{array}$ & $\begin{array}{l}0.75(0.47 \\
1.21)\end{array}$ & 0.245 & $\begin{array}{l}0.84(0.51 \\
1.36)\end{array}$ & 0.488 \\
\hline $\begin{array}{l}\text { Preterm } \\
\text { premature } \\
\text { rupture of } \\
\text { the mem- } \\
\text { branes } \\
\text { f }\end{array}$ & $\begin{array}{l}42 / 1272 \\
(3.3)\end{array}$ & $12 / 263(4.7)$ & $\begin{array}{l}30 / 1019 \\
(2.9)\end{array}$ & $\begin{array}{l}0.83(0.41, \\
1.69)\end{array}$ & 0.616 & $\begin{array}{l}0.99(0.47 \\
2.07)\end{array}$ & 0.987 \\
\hline $\begin{array}{l}\text { Preterm } \\
\text { birth }^{f}\end{array}$ & $\begin{array}{l}82 / 1272 \\
(6.4)\end{array}$ & $\begin{array}{l}21 / 253 \\
(8.3)\end{array}$ & $\begin{array}{l}61 / 1019 \\
(5.9)\end{array}$ & $\begin{array}{l}0.95(0.56 \\
1.60)\end{array}$ & 0.852 & $\begin{array}{l}0.99(0.57 \\
1.70)\end{array}$ & 0.984 \\
\hline $\begin{array}{l}\text { Spontaneous } \\
\text { preterm } \\
\text { birth }{ }^{f} \\
\text { Birth } \\
\text { outcomes }\end{array}$ & $\begin{array}{l}51 / 1272 \\
(4.0)\end{array}$ & $\begin{array}{l}14 / 253 \\
(5.5)\end{array}$ & $\begin{array}{l}37 / 1019 \\
(3.6)\end{array}$ & $\begin{array}{l}0.87(0.46 \\
1.67)\end{array}$ & 0.693 & $\begin{array}{l}1.01(0.52, \\
1.97)\end{array}$ & 0.961 \\
\hline $\begin{array}{l}\text { LBW } \\
(<2500 \mathrm{~g})\end{array}$ & $\begin{array}{l}71 / 1268 \\
(5.6)\end{array}$ & $\begin{array}{l}21 / 250 \\
(8.4)\end{array}$ & $\begin{array}{l}50 / 1018 \\
(4.9)\end{array}$ & $\begin{array}{l}0.69(0 . \\
40,1.19)\end{array}$ & 0.189 & $\begin{array}{l}0.72(0.41 \\
1.27)\end{array}$ & 0.261 \\
\hline $\begin{array}{l}\text { LBW at } \\
\text { term } \\
(<2500 \mathrm{~g}) \\
\mathrm{g}\end{array}$ & $\begin{array}{l}31 / 1186 \\
(2.6)\end{array}$ & $\begin{array}{l}8 / 229 \\
(3.4)\end{array}$ & $\begin{array}{l}23 / 957 \\
(2.4)\end{array}$ & $\begin{array}{l}0.64(0.28 \\
1.46)\end{array}$ & 0.299 & $\begin{array}{l}0.67(0.29 \\
1.55)\end{array}$ & 0.361 \\
\hline SGA & $\begin{array}{l}150 / 1266 \\
(11.8)\end{array}$ & $36 / 249(14.4)$ & $\begin{array}{l}114 / 1017 \\
(11.2)\end{array}$ & $\begin{array}{l}0.77(0.52, \\
1.15) \\
\text { Difference } \\
\text { in means } \\
\text { (vacci- } \\
\text { nated - } \\
\text { unvacci- } \\
\text { nated) }\end{array}$ & $\begin{array}{l}0.211 \\
\text { Difference } \\
\text { in means } \\
\text { (vacci- } \\
\text { nated - } \\
\text { unvacci- } \\
\text { nated) }\end{array}$ & $\begin{array}{l}0.80(0.53, \\
1.20) \\
\text { Difference } \\
\text { in } \\
\text { adjusted } \\
\text { means } \\
\text { (vacci- } \\
\text { nated } \\
\text { - } \\
\text { unvaccinat }\end{array}$ & $\begin{array}{l}0.295 \\
\text { Difference } \\
\text { in } \\
\text { adjusted } \\
\text { means } \\
\text { (vacci- } \\
\text { nated } \\
\text { - } \\
\text { )unvaccinat }\end{array}$ \\
\hline $\begin{array}{l}\text { Mean birth } \\
\text { weight, } \\
\text { grams }(95 \% \\
\text { CI) }\end{array}$ & $\begin{array}{l}3368.0 \pm \\
496.2\end{array}$ & $\begin{array}{l}3313 \pm \\
565.3\end{array}$ & $\begin{array}{l}3381.2 \pm \\
477.5\end{array}$ & $\begin{array}{l}68.0(-3.0 \\
139.1)\end{array}$ & 0.061 & $\begin{array}{l}44.6(-26.0 \\
115.3)\end{array}$ & 0.216 \\
\hline
\end{tabular}




\begin{tabular}{|c|c|c|c|c|c|c|c|}
\hline $\begin{array}{l}\text { Pregnancy } \\
\text { outcomes }\end{array}$ & Total $^{\mathrm{a}}$ & $\begin{array}{l}\text { Unvaccinated } \\
\mathrm{N}(\%)\end{array}$ & $\begin{array}{l}\text { Vaccinated } \\
\mathrm{N}(\%)\end{array}$ & $\begin{array}{l}\text { Crude HR }{ }^{b} \\
(95 \% \text { CI })\end{array}$ & $\mathrm{p}$-value & $\begin{array}{l}\text { Adjusted }{ }^{\mathrm{c}} \\
\text { aHR }(95 \% \\
\mathrm{CI})\end{array}$ & $\mathrm{p}$-value \\
\hline $\begin{array}{l}\text { Mean ges- } \\
\text { tational } \\
\text { age at } \\
\text { delivery, } \\
\text { weeks } \\
(95 \% \mathrm{CI})\end{array}$ & $39.4 \pm 1.5$ & $39.2 \pm 1.7$ & $39.4 \pm 1.4$ & $\begin{array}{l}0.23(0.01 \\
0.44)\end{array}$ & 0.038 & $\begin{array}{l}0.22 \\
(0.001 \\
0.44)\end{array}$ & 0.048 \\
\hline
\end{tabular}

$\mathrm{CI}=$ confidence interval. $\mathrm{HR}=$ hazard ratios. $\mathrm{LBW}=$ low birthweight. $\mathrm{SGA}=$ small for gestational age

a: Denominators differ due to missing data.

b: HR results compared outcome variable in vaccinated group to reference (unvaccinated).

c: Adjustments were made for maternal age, race/ethnicity, education, household income, gravidity, intake of alcohol and recreational drugs, smoking, pre-pregnancy body mass index (continuous), use of multivitamin supplements, estimated season of delivery, Edinburgh Postnatal. Depression Scale (EPDS), The StateTrait Anxiety Inventory (STAI), Perceived Stress Scale (PSS-10), physical activity, infertility treatment, and asthma. Birth outcomes were additionally adjusted for infant's sex.

d: For hypertensive disorders analysis, women who were vaccinated at or after the gestational age at diagnosis were censored

e: Women admitted to hospital with respiratory tract infection/influenza-like illness were censored at their admission date

f: Women vaccinated at 37 weeks' or later were censored because they were no longer at risk of preterm birth.

g: Low birthweight at term ( $<2500 \mathrm{~g}$ and [?] 37 completed weeks' gestation at birth).

Table 3: Pregnancy and birth outcomes following pertussis vaccination during pregnancy at two obstetric hospitals in South Australia 2015-2018

\begin{tabular}{|c|c|c|c|c|c|c|c|}
\hline $\begin{array}{l}\text { Pregnancy } \\
\text { outcomes }\end{array}$ & Total $^{\mathrm{a}}$ & $\begin{array}{l}\text { Unvaccinated } \\
\mathrm{N}(\%)\end{array}$ & $\begin{array}{l}\text { Vaccinated } \\
\mathrm{N}(\%)\end{array}$ & $\begin{array}{l}\text { Risk Ratios } \\
\text { RR }(95 \% \\
\text { CI })\end{array}$ & $\mathrm{p}$-value & $\begin{array}{l}\text { Adjusted b } \\
\text { aRR }(95 \% \\
\text { CI) }\end{array}$ & $\mathrm{p}$-value \\
\hline $\begin{array}{l}\text { Chorioamnioni } \\
\text { and/or } \\
\text { funisitis }\end{array}$ & $\begin{array}{l}\operatorname{tP3} 3 / 1272 \\
(1.8)\end{array}$ & $\begin{array}{l}7 / 253 \\
(2.7)\end{array}$ & $\begin{array}{l}16 / 1019 \\
(1.5)\end{array}$ & $\begin{array}{l}0.52(0.21 \\
1.26)\end{array}$ & 0.149 & $\begin{array}{l}0.71(0.27, \\
1.82)\end{array}$ & 0.481 \\
\hline $\begin{array}{l}\text { Placental } \\
\text { abruption }\end{array}$ & $\begin{array}{l}32 / 1266 \\
(3.3)\end{array}$ & $\begin{array}{l}7 / 250 \\
(2.8)\end{array}$ & $\begin{array}{l}25 / 1016 \\
(2.4)\end{array}$ & $\begin{array}{l}0.90(0.37 \\
2.20)\end{array}$ & 0.833 & $\begin{array}{l}1.04(0.41, \\
2.62)\end{array}$ & 0.923 \\
\hline $\begin{array}{l}\text { Postpartum } \\
\text { haemorrhage } \\
\text { Birth } \\
\text { outcomes }\end{array}$ & $\begin{array}{l}115 / 1269 \\
(9.0)\end{array}$ & $\begin{array}{l}26 / 251 \\
(10.3)\end{array}$ & $\begin{array}{l}89 / 1018 \\
(8.7)\end{array}$ & $\begin{array}{l}0.85(0.55 \\
1.31)\end{array}$ & 0.475 & $\begin{array}{l}0.81(0.52, \\
1.26)\end{array}$ & 0.357 \\
\hline $\begin{array}{l}\text { Apgar at } \\
1 \text { min }<7\end{array}$ & $\begin{array}{l}149 / 1263 \\
(11.8)\end{array}$ & $\begin{array}{l}30 / 247 \\
(12.1)\end{array}$ & $\begin{array}{l}119 / 1016 \\
(11.7)\end{array}$ & $\begin{array}{l}0.91(0.62, \\
1.34)\end{array}$ & 0.646 & $\begin{array}{l}0.87(0.59, \\
1.29)\end{array}$ & 0.496 \\
\hline $\begin{array}{l}\text { Apgar at } \\
5-\min <7\end{array}$ & $\begin{array}{l}26 / 1265 \\
(2.0)\end{array}$ & $\begin{array}{l}6 / 248 \\
(2.4)\end{array}$ & $\begin{array}{l}20 / 1017 \\
(1.9)\end{array}$ & $\begin{array}{l}0.84(0.31 \\
2.25)\end{array}$ & 0.738 & $\begin{array}{l}0.75(0.27, \\
2.06)\end{array}$ & 0.582 \\
\hline
\end{tabular}




\begin{tabular}{|c|c|c|c|c|c|c|c|}
\hline $\begin{array}{l}\text { Pregnancy } \\
\text { outcomes }\end{array}$ & Total $^{\mathrm{a}}$ & $\begin{array}{l}\text { Unvaccinated } \\
\mathrm{N}(\%)\end{array}$ & $\begin{array}{l}\text { Vaccinated } \\
\mathrm{N}(\%)\end{array}$ & $\begin{array}{l}\text { Risk Ratios } \\
\text { RR (95\% } \\
\text { CI) }\end{array}$ & $\mathrm{p}$-value & $\begin{array}{l}\text { Adjusted b } \\
\text { aRR }(95 \% \\
\text { CI })\end{array}$ & p-value \\
\hline $\begin{array}{l}\text { Admitted } \\
\text { to } \\
\text { Neonatal } \\
\text { unit }^{c}\end{array}$ & $\begin{array}{l}285 / 1272 \\
(22.4)\end{array}$ & $\begin{array}{l}65 / 253 \\
(25.6)\end{array}$ & $\begin{array}{l}220 / 1019 \\
(21.5)\end{array}$ & $\begin{array}{l}0.81(0.64, \\
1.04)\end{array}$ & 0.115 & $\begin{array}{l}0.84(0.66, \\
1.07)\end{array}$ & 0.177 \\
\hline $\begin{array}{l}\text { Respiratory } \\
\text { distress } \\
\text { syndrome }\end{array}$ & $\begin{array}{l}10 / 1272 \\
(0.7)\end{array}$ & $\begin{array}{l}3 / 253 \\
(1.1)\end{array}$ & $\begin{array}{l}7 / 1019 \\
(0.6)\end{array}$ & $\begin{array}{l}0.56(0.14, \\
2.16)\end{array}$ & 0.406 & $\begin{array}{l}0.61(0.20, \\
1.82)\end{array}$ & 0.384 \\
\hline $\begin{array}{l}\text { Mechanical } \\
\text { ventilation }\end{array}$ & $\begin{array}{l}42 / 1272 \\
(3.3)\end{array}$ & $\begin{array}{l}9 / 253 \\
(3.5)\end{array}$ & $\begin{array}{l}33 / 1019 \\
(3.2)\end{array}$ & $\begin{array}{l}0.78(0.38, \\
1.63)\end{array}$ & 0.526 & $\begin{array}{l}0.71(0.34, \\
1.50)\end{array}$ & 0.381 \\
\hline
\end{tabular}

a: Denominators differ due to missing data.

b: Pregnancy outcomes were adjusted for maternal age, ethnicity, total years of full-time education, household income, gravidity, intake of alcohol and recreational drugs, smoking, pre-pregnancy body mass index (continuous), use of multivitamin supplements, Edinburgh Postnatal Depression Scale (EPDS), The StateTrait Anxiety Inventory (STAI), Perceived Stress Scale (PSS-10), physical activity, infertility treatment and asthma. Birth outcomes were additionally adjusted for infant's sex.

c: Reasons for admission: preterm, respiratory distress infection, feeding problem, hypoglycaemia, drug withdrawal, SGA, birth asphyxia, congenital abnormality, phototherapy and cyanosis. 




